DEPARTMENT OF THE INTERIOR

UNITED STATES GEOLOGICAL SURVEY

\title{
AEROMAGNETIC MAP OF EAST-CENTRAL UNITED STATES
}

By T.G. Hildenbrand, R.P. Kucks, and R.W. Johnson, Jr. 